P019

\title{
CONTROLLED SPECTRAL POWER DISTRIBUTION METHOD TO IMPROVE VISUAL ACUITY IN THE MESOPIC AND SCOTOPIC STATES OF VISION, FOR OUTDOOR LIGHTING APPLICATIONS
}

\author{
Rohan Nag
}

DOI 10.25039/x47.2020.PO19

\section{Paper accepted for the $5^{\text {th }}$ CIE Symposium on Colour and Visual Appearance}

The paper was selected by the International Scientific Committee (ISC) for presentation at the 5th CIE Symposium on Colour and Visual Appearance, Hong Kong, CN, April 21-22, 2020, which, due to the corona pandemic, could not take place. The paper has not been peer-reviewed by CIE.

\section{(C) CIE 2020}

All rights reserved. Unless otherwise specified, no part of this publication may be reproduced or utilized in any form or by any means, electronic or mechanical, including photocopying and microfilm, without permission in writing from CIE Central Bureau at the address below. Any mention of organizations or products does not imply endorsement by the CIE.

This paper is made available open access for individual use. However, in all other cases all rights are reserved unless explicit permission is sought from and given by the CIE.

CIE Central Bureau

Babenbergerstrasse 9

A-1010 Vienna

Austria

Tel.: +4317143187

e-mail: ciecb@cie.co.at

www.cie.co.at 


\title{
P019 \\ CONTROLLED SPECTRAL POWER DISTRIBUTION METHOD TO IMPROVE VISUAL ACUITY IN THE MESOPIC AND SCOTOPIC STATES OF VISION, FOR OUTDOOR LIGHTING APPLICATIONS
}

\author{
Nag, R. \\ Regent Lighting, Bangalore, INDIA \\ rohan.studsat@gmail.com
}

\begin{abstract}
Rapid transition from conventional to solid state lighting combined with the lack of technical understanding on outdoor lighting applications and human vision perception, poses a serious threat to the nocturnal ecology and the health and safety of human beings. In an experimental setup, by varying the relative spectral power of a luminous source in an outdoor environment; we are able to test and validate a significant increase in responsivity and decrease in metamerism under low and very low lighting conditions.
\end{abstract}

\section{Motivation}

In the past decade the world has witnessed an increasing number of companies, emerging in the solid state lighting industry. Under a stiff competitive environment, numerous projects are being executed where, utmost importance is given to achieve and maintain the photopic lux but almost no calculation on the rendering conditions in the mesopic and the scotopic states are ever emphasized. The inability to understand the lighting applications completely, its demands, parameters, etc. along with the failure to leverage the current scientific breakthroughs in the field of solid state control technologies has not only resulted in the increased lighting points \& lighting levels causing light pollution from surface scattering \& direct spill light, but also reduced human visual acuity in many instances.

The motivation for this technical paper comes from the numerous years spent and the numerous challenges faced through those years, in the fields of light planning, designing, installing and commissioning various lighting applications. Also the recent advancements in human circadian lighting mechanisms and the current quest towards defining the visual adaptation field to quantify the adaptation luminance, have all been a source of inspiration for this paper.

\section{Method}

To have a comprehensive understanding of the solution, we have shortlisted one of several real world problem statements that will have the maximum impact, if solved. After thorough investigation, we implemented the test procedures at the experimental setup and observed the results over multiple iterations. The problem statement considered, is of the night time poor visibility issue at coastal areas under infrastructure lighting. Unlike the widely known phenomenon of water vapour condensing on airborne salt particles causing fog which scatters light beams from a solid state lighting source, which were intended to uniformly reach the target application surface; the night time sea fog is actually caused when cold air passes over moist warm lands. Experimental setup as depicted in Figure 1. In such a situation, the problem of poor visibility cannot be addressed by the currently used methods of either increasing the luminous intensity intended per unit area of the application or altering the beam angle of the luminaire between wide and narrow beams. The probable solution takes inspiration from the previous lighting technology used in these applications, the high pressure sodium vapour lamps. With a low correlated colour temperature and lower colour rendering index, the HPSV technology had catered to the visibility issue for years but had eventually phased out because of high operational costs and frequent maintenance needs. 


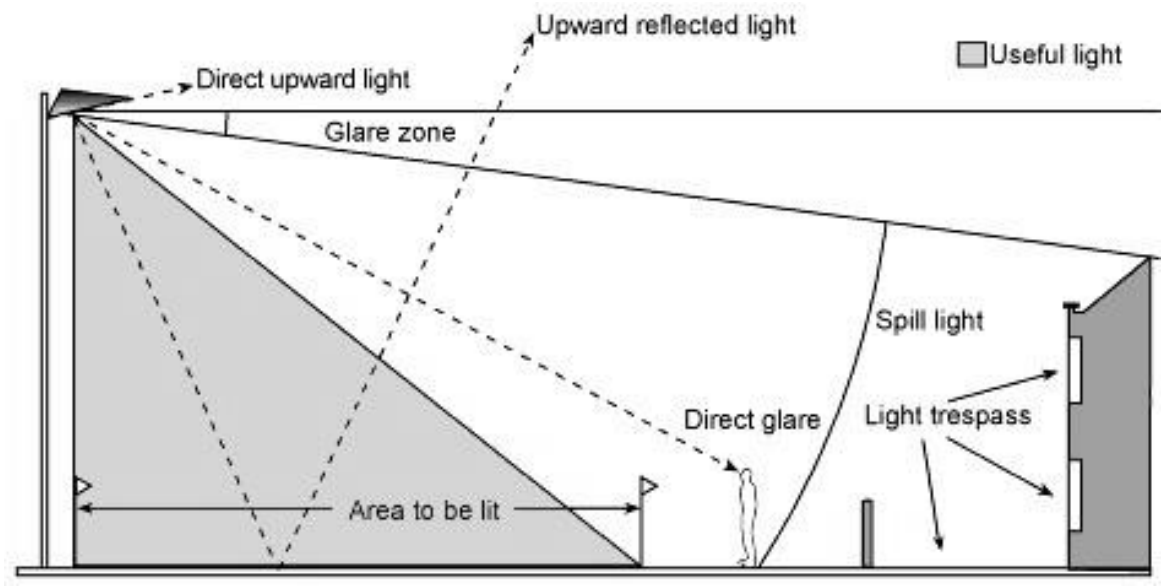

Figure 1 - Infrastructure Lighting Application

The hardware construction of the experimental setup consists of two parts. Three numbers of LED's Red, Green and Blue soldered together on a PCB as a single unit with a dedicated lens on each PCB unit, collectively enclosed in a clear polycarbonate diffuser; forms the optical compartment. The hardware was initially tested with the LED chips, depicted in Figures 2 and 3.

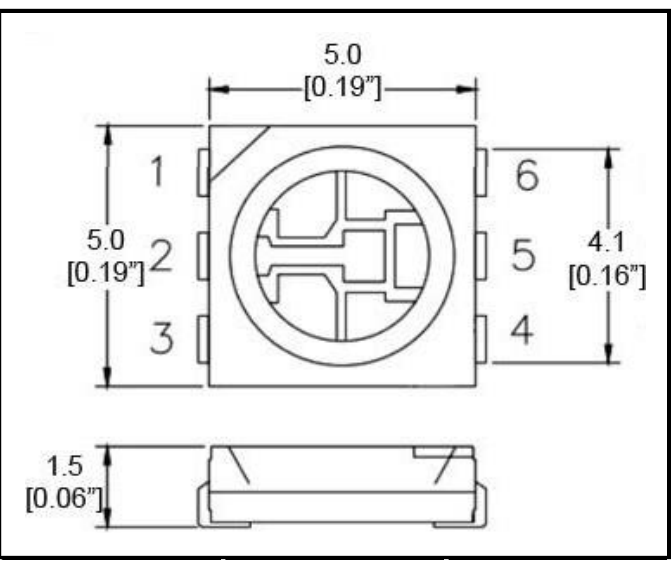

Figure 2 - RGBW LED Chip

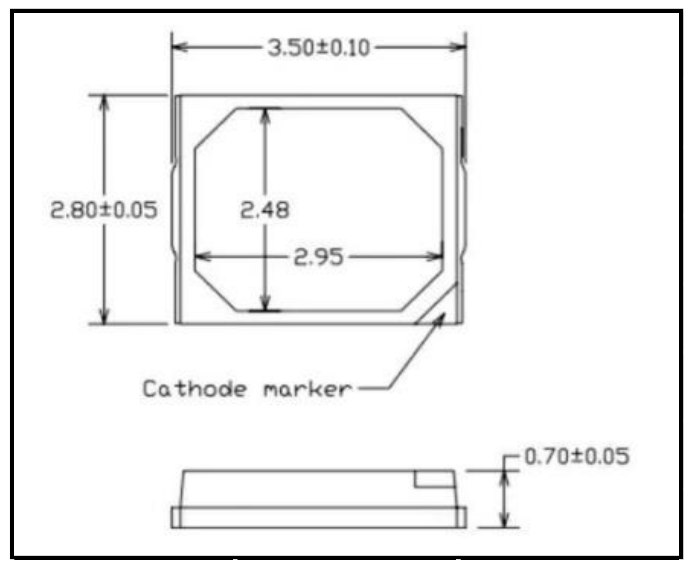

Figure 3 - Tunable LED Chip

The spectral power distribution module with its multichannel control lines to the PCB's are enclosed in the driver compartment, connected to a secure server over a virtual LAN. The software construction consists of a data intake system that draws real-time data from an astronomical clock and a local weather station. The data is assembled on a single platform and analysed by a centrally housed algorithm. In every ten minutes, the spectral power control data for various zones of the application is transmitted wirelessly. 

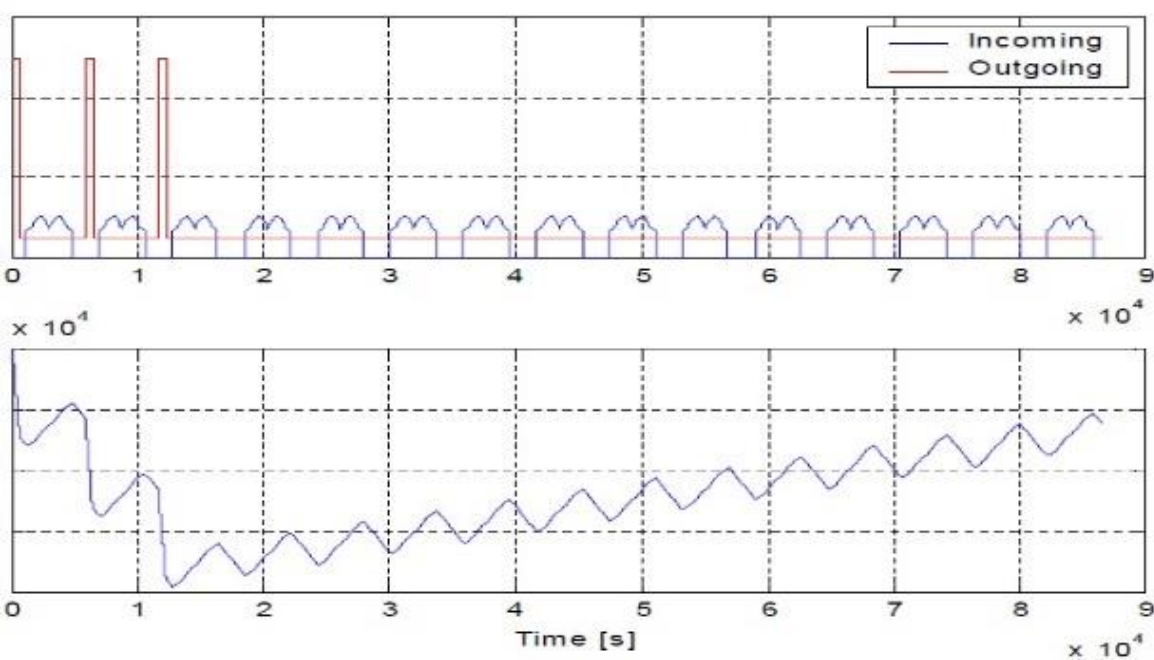

Figure 4 - Test Indicating Increase in Responsivity on the Simulator

To better understand the suitable applications of this technology, we conducted an experiment between two different lighting designs with the use of the same SPD unit. Below Figure 5 depicts the direct lighting application and the Figure 6 depicts the volumetric lighting application (light sources placed at equal but angular locations)

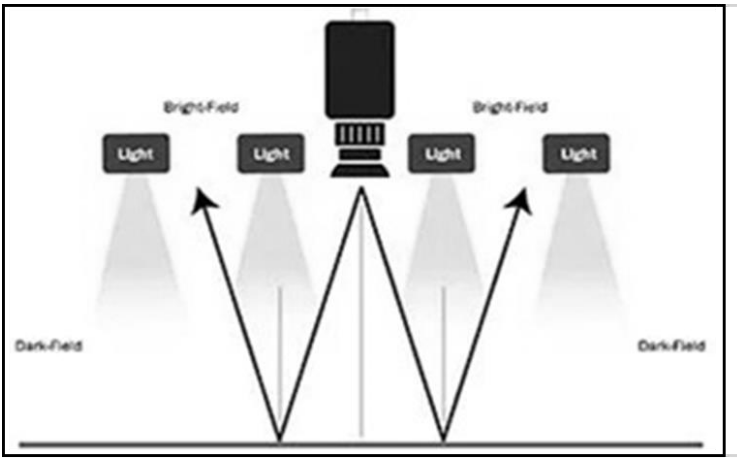

Figure 5 - Direct Application

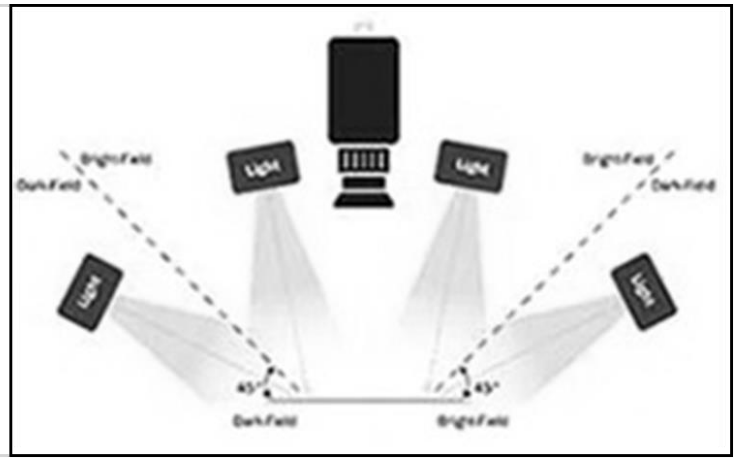

Figure 6 - Volumetric Application

Four different beams were selected for each application. A wide, narrow, dual asymmetric and asymmetric beams. Each beam was used for several hours to study the transitions between the mesopic to scotopic and scotopic back to mesopic states. 

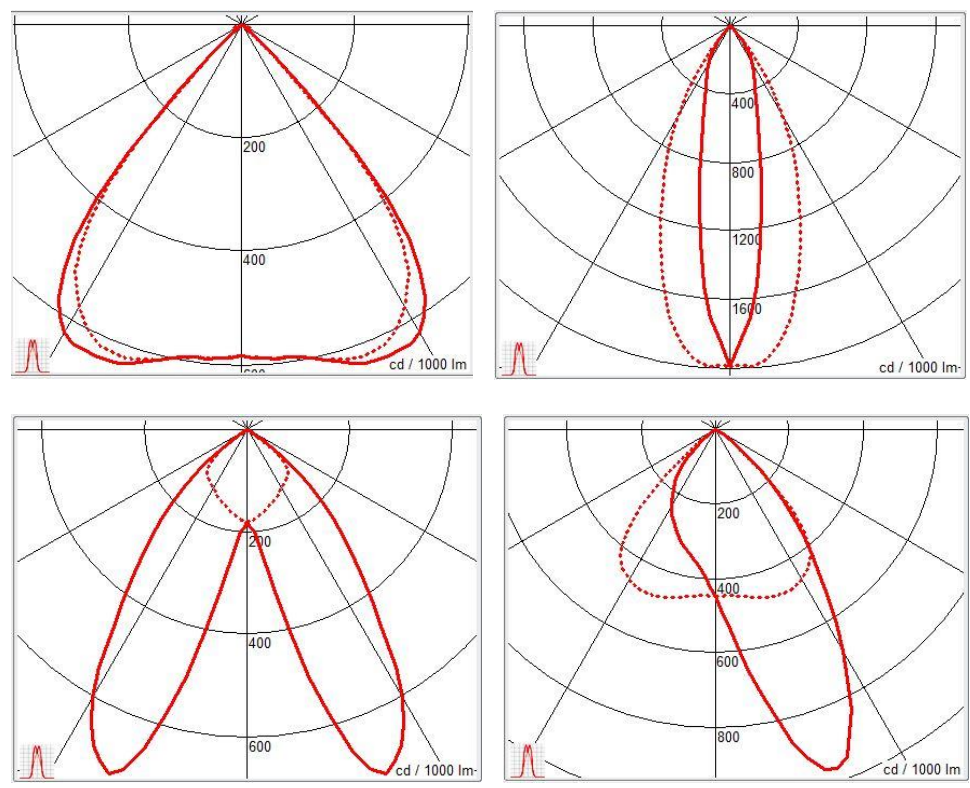

Figure 7 - Four Different Beams Applied

With the completion of the initial experiment, we were able to plot the resultant data and draw our conclusions; formulate our aim for the next set of experiments and parameters to consider.

\section{Results}

The experimental setup was simulated and run from dusk to dawn, continuously for a week. We observed the gradual change in $\mathrm{W} \cdot \mathrm{m}^{-2} \cdot \mathrm{nm}^{-1}$ for different application zones depending upon the variable input data set. The intensity was intentionally varied under harsh weather conditions, as to enter the mesopic $0.01 \mathrm{~cd} / \mathrm{m}^{2}$ to $3 \mathrm{~cd} / \mathrm{m}^{2}$ state of vision, then the scotopic $10^{-3} \mathrm{~cd} / \mathrm{m}^{2}$ to $10^{-6} \mathrm{~cd} / \mathrm{m}^{2}$ state of vision and back to the mesopic state of vision. The experiment was repeated several times and the observations were tabulated. Improvements in the backend algorithm was done repeatedly after every round of experimentation. Currently we are attempting to narrow down on the results for a better understanding of the human vision perception and phenomenon. The plotted results from the experiment is described in the Chart 1, below. We now understand that direct lighting application has a higher rate of responsivity vs the volumetric application, since the spectrally tuned wave gets heavily distorted with the increase in overall distance from the source; because of scattering.

Chart 1 - Difference in Measured Responsivity

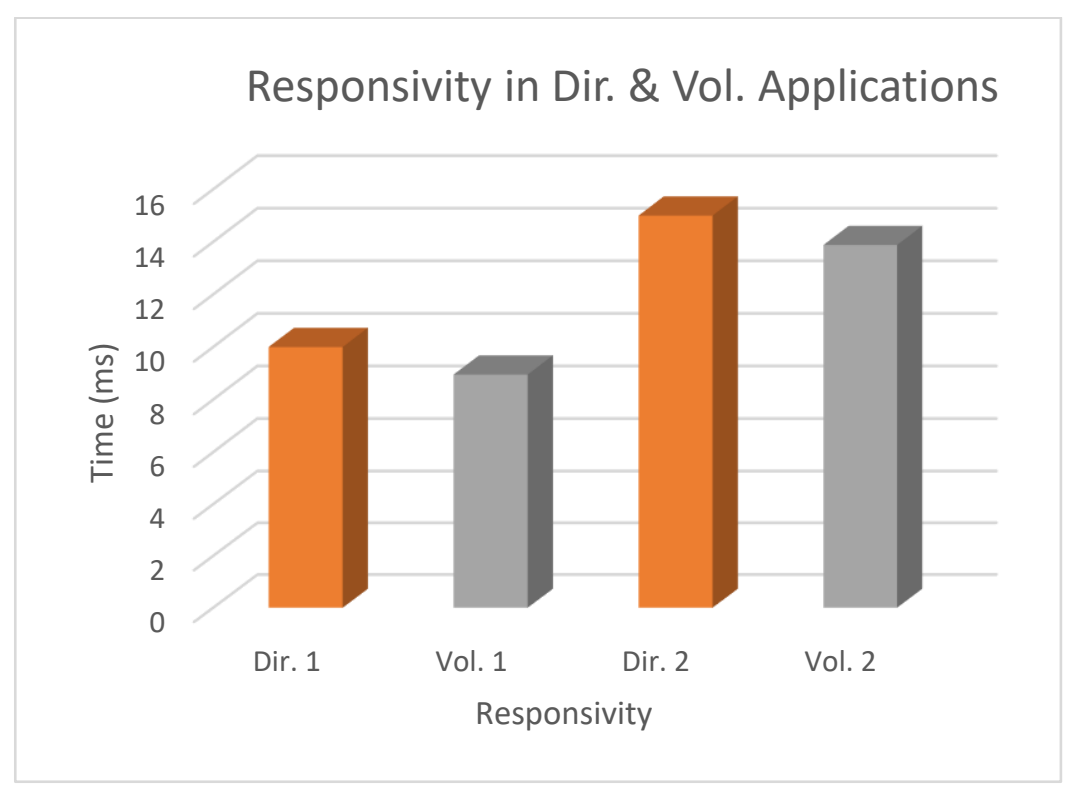


The above discussed procedure was also tested with a different control parameter set, for a heavy manufacturing industry; to address the issue of metamerism on the assembly floor. Significant increase in the quality of workmanship was observed.

\section{Conclusion}

From the above experimental setup and the subsequent understanding gathered over a period of few months, we can deduce that; implementing a controlled spectral power distribution method in outdoor lighting fixtures, helps in improving human vision without causing harm to the nocturnal ecosystem. The sole intention of writing this scientific paper is to propose, debate and discuss the very need for a deeper understanding of the mesopic and its transition to and from the scotopic state of human vison and the conditions governing them. We find ourselves in full confidence that a mesh network of intelligent spectral power distribution units can be implemented in different lighting applications, world across to reduce risks and improve overall wellbeing. We hope that the spirit of scientific enquiry in this field will generate feedback and criticism; from which we shall draw the ways of improvement of this technology, in the near future. 